\title{
Evaluation of the Effect of Capillary Rise of Salt Water on Structural Reinforcement in Reinforced Concrete
}

\author{
Ehichioya, I., Okodugha, D. A. \& Oboh, A.A. \\ Department of Civil Engineering \\ Auchi Polytechnic, Auchi \\ Edo State, Nigeria. \\ Email : abichioya2000@yahoo.co.uk
}

\begin{abstract}
The project focuses on evaluating the effect of capillary rise of salt water on structural reinforcement. In the study, the effect of saline water on the properties of concrete was investigated. A mix design of 1:1.5:3, using constant water cement ratio $(\mathrm{w} / \mathrm{c})$ of 0.40 by weight was adopted for batching the various components of the constituents' materials for this experiment. Concrete elements were cast and cure with salt water while fresh water was used as a control experiment. A total of forty-eight (48) concrete cubes and cylinder were cast using measured quantity of $5 \mathrm{mg} / \mathrm{l}$, $10 \mathrm{mg} / \mathrm{l}$, and $20 \mathrm{mg} / \mathrm{l}$ saline water. The concrete cubes were cured and tested for $7,14,21$, and 28 days respectively. The results that both the compressive strength and Split tensile strength of concrete obtained shows an increment in strength development irrespective of the salt content in the water. Fresh water was still most suitable for concrete production
\end{abstract}

Keywords: Concrete, Water, Compressive Strength, Capillary Action and Reinforcement

Aims Research Journal Reference Format:

Ehichioya, I., Okodugha, D. A. \& Oboh, A.A. (2018): Evaluationof the Effect of Capillary Rise of Salt Water on Structural Reinforcement in Reinforced Concrete. Advances in Multidisciplinary \& Scientific Research Journal. Vol. 4. No.4.

Pp 53-62. Available online at www.aimsjournal.net. - DOI - dx.doi.org/10.22624/AIMS/V4N4P6

\section{INTRODUCTION}

Most characteristics of concrete depend on moisture content, hardened concrete absorbs large amounts of water faster by capillary action if the surface gets temporarily wet or is permanently in contact with water. Capillary suction of water is an efficient mechanism for transport of dissolved salts such as sulphates, chlorides, and ammonium compounds into the porous structure of concrete. This ion migration or movement is known to be the origin of most frequently deterioration of reinforced concrete structures in aggressive environment. It has been shown recently that capillary action can be practically suppressed by surface impregnation of concrete with liquid silanes. In practice and for some cases at least, it would be beneficial, if the entire volume of a structural element could be water repellent and not only have the areas closed to the surface (Prascal et al, 2006). This goal can be reached in principle at least, by adding saline emulsion to the fresh mix of cement based materials. Materials produced in this way may be called integral water repellent concrete or mortar.

Concrete has considerable crushing strength, is durable, has good resistance to fire but offers little or no strength in tension but fair in shear. On the other hand, steel has a very good tensile property, poor resistance to fire (due to rapid loss of strength under high temperature) and very good both in shear and in compression. Thus, a combination of these materials results in good tensile and compressive strength, durability and good resistance to fire and shear. The quality of concrete in a broad sense is considered as a cause or factor that could be responsible for the deterioration of concrete and not any isolated factor. But, in tackling deterioration of concrete, the salinity effect must never be left out as it usually come into the scene most especially when water of its constituent is used or when concrete is being worked upon in region of its (salt) reach. This study will be of high importance to the construction team involved in the erection of building especially Builder, Civil and Structural engineer in order to increase their knowledge on how salinity can affect the structural stability and environment of a particular building. The study critically examines to determine the reinforced concrete strength in relation to its mix proportion and its age. It also examines the usual stripping days for formworks and identifies adequate precautions to be taken in the execution of such works. The study assessed coastal region salinity, its measurement and classification and also considers the effect of salt water of coastal areas on the compressive strength of concrete. 
Concrete in marine environment suffer deterioration which may be due to the effects of chemical reaction of seawater constituents with cement hydration products, alkali-aggregate expansion which occur when reactive aggregates are present, crystallization pressure of salts within concrete when one face of the structure is subject to wetting and others to drying conditions, frost action in cold climates (Akinkurolere et al, 2007). Corrosion of embedded steel in reinforced or prestressed members, and physical erosion due to wave action and floating objects (Mokhtar and Swamy, 2008; Gopal, 2010). Mehta and Monteiro, (2006) in Akinkurolere et al, (2007) also noticed that concrete can deteriorate by stresses caused by crystallization of salts in the pores when one side of a slab or retaining wall of a permeable solid is in contact with a salt solution and the other sides are subjected to loss of moisture by evaporation. It is well-known that moisture plays a key role in nearly all deteriorating processes in concrete and reinforced concrete structures. The sorption isotherm clearly indicates that at low relative humidity $(\mathrm{RH}<50 \%)$ most of the water is absorbed on the huge internal surface of the hydration products.

A series of deteriorating processes can take place while the pore solution interacts with the solid skeleton formed by the hydration products such as hydrolyzis, alkali-silica reaction, and carbonation. Furthermore in case of high moisture content frost sensitivity becomes a serious risk. High moisture content leads also to high electric conductivity and as a consequence high rate of corrosion of steel reinforcement in carbonated or chloride contaminated concrete. The high thermal conductivity of humid concrete can cause serious damage in dwellinghouses in particular. The crust and interior of the earth constitutes the main source of seas. Salinity, which is measured in terms of, dissolved materials per kilogram of sea water or equivalently parts per thousand, represents the total quantity of dissolved salt in seawater. Vicat (1812) opine that the world seawater in most cases has salinity of the range (34-35) \% though the properties of water to dissolved salts tend to vary within the ocean, the major component ions are evenly distributed in ocean water in relatively constant proportion that accounts for the defects and failures of buildings located in coastal areas.

The research provides information on capillary rise of salt water on structural reinforcement: which eventually culminate in process of steel corrosion in reinforced concrete members and the factors influencing the process. In order to protect the steel bars from corrosion, the corrosion process and its occurrence needs to be understood. An example for simple corrosion process is the observation that a steel bar that is kept in the air or is immersed in water corrodes at a very slow rate when compared to a steel bar that is subjected to wetting and drying cycles. Therefore, a steel bar corrodes faster in the presence of air and water. As concrete contains moisture due to its porous nature, why doesn't the steel embedded in concrete corrode? This is the first question that needs to be answered in order to understand the corrosion process for steel embedded in concrete.

The answer to the above question is that concrete is alkaline is nature. Metals (steel) corrode in an acidic environment, and alkalinity is opposite of acidity, so metals are protected from corrosion by the alkalis in the concrete. The next question is Why is concrete alkaline? The micro-voids of the concrete contain high concentration of the oxides calcium, sodium and magnesium. In the presence of water (in the pores) these oxides produce hydroxides that are highly alkaline in nature, with a $\mathrm{pH}$ in the range of 12.5 to 13.5 (Villmann, 2007). $\mathrm{pH}$ is defined as a negative logarithm of the hydrogen ions concentration in the solution. A general description of $\mathrm{pH}$ is that it's a measure of acidity or alkalinity of the solution (based on the concentration of hydrogen ions). When $\mathrm{pH}=1$, the solution is very acidic; and when $\mathrm{pH}=14$, it is highly basic (or alkaline) (Schweitzer, 2010). The high alkalinity of the concrete pore water leads to the formation of a passive layer on the steel surface. This passive layer, which is the combination of oxides and hydrogen of iron and the minerals from the cement, will protect the steel from corrosion. However, over a period of time, this layer is destroyed by carbonation of concrete and/or chloride attack, which will result in active corrosion of the steel embedded in concrete (Medeiros and Helene, 2008).

\subsection{Statement of the Problem}

Deterioration of reinforced concrete $(\mathrm{RC})$ structures causes many problems. One of the major deterioration mechanisms in reinforced concrete members is reinforcement corrosion due to capillary rise of moisture. Reinforced concrete structures in all parts of the world, are suffering from deterioration due to capillary rise of salt water on structural reinforcement. It was estimated in 1997 that the costs associated with corrosion damage to bridges in the United States exceeded $\$ 150$ billion (Esfahani and Rangan, 2000).

Another key issue is the negligence of capillary rise of salt water, poor inspection and lack of knowledge on-site leading to collapse of structures, which can lead to loss of life and property. Therefore, structural damage and economic loss caused by capillary rise of salt water which eventually lead to corrosion is a very serious problem and is being addressed by many researchers. Engineers should have an in-depth knowledge of the corrosion process, its occurrence, and its effects on structural integrity. 


\subsection{Aim and Objectives}

The aim of this research is to evaluate the effect of capillary rise of salt water on structural reinforcement. In order to achieve this aim, the following objectives have been set:

(i) This study provides a better understanding about the levels of capillary rise of salt water and their effects on bond strength between reinforcement and concrete.

(ii) The study is to develop understanding of the relationship of capillary rise of salt on structural reinforcement levels with cracks and also the relationship between cracking and bond strength of reinforced concrete.

(iii) To determine the various level of corrosion of embedded steel bars in reinforced concrete as the level of capillary rises of salt water.

\subsection{Effects of Salt Water on Concrete}

Salt water is corrosive. In fact it is a problem that engineers have been faced with for some time in regards to larger concrete structures like sea walls. Salt water itself contains magnesium chloride, sulfate ions and hydrogen carbonation ions that will essentially attack concrete to a certain degree, but what really starts to corrode in a concrete structure is any of the steel substructure within. Concrete contains an alkaline environment that provides some protection against corrosion. The steel inside the concrete that is used for reinforcement will react with the concrete and form film that protects the steel (parrot, 2006).

The chloride and sulfate ions will weaken that film as the water soaks into the concrete. Once the film is breached, then the corrosion process begins to work on the steel itself. Have you ever seen rust stains coming out of concrete? Usually these stains appear around a small fissure or crack. The fissure or crack would have been the most likely place for the salt water to enter. Because concrete is a type of porous material, oxygen and humidity can be present at the point the salt water has come into contact with the film. This is when the corrosion process of the steel will begin. This is also the point where things can go bad. Now granted, this is not an overnight process. Generally this process is gradual, but environmental conditions can accelerate the process. Building a holding tank for saltwater aquaria risks this sort of corrosion if not properly protected. Going back to the steel in the concrete, this being wires mesh of rebar, this normally just simple carbon steel. When carbon steel corrodes, it expands. Have you ever found something old that's made of steel that has become all rusty? You recognize the item, but it's usually a lot bigger than it was when it was new.

\subsection{Salinity Measurement}

Adebakin (2003) described fresh water as the most purified form of water; it is devoid of any form of impurities. While saltwater is known as water containing high level of Sodium chloride (Nacl). Only 2.5 Percent of the world's water bodies is said to be fresh water, the remaining constitute seawater.

\subsection{Reinforcement Corrosion}

Reinforcement corrosion is a complex electrochemical process, where the progress of the process depends on the permeability, electric potential and electric resistance of concrete. The corrosion of reinforcement steel occurs in the presence of water and oxygen where iron oxide is formed, known as rust. By development of corrosion, brown stains form on the concrete surface and characteristic cracks form along reinforcement bars, especially in the corners of the elements where they are exposed to penetration of aggressive matter into concrete. Since rust occupies a larger volume than steel, development of rust brings about cracking and failing of concrete and facilitates further penetration of aggressive matter.

\subsection{Concrete}

A composite materials consisting of building medium or glue i.e. cement and water) in which particles of a relatively inert filter materials (i.e. sand and granite aggregate) are embedded is called concrete. Properties of a concrete is improved or modified occasionally through the application of materials called Admixture. The basic components constituting materials in a concrete are cement, fine and coarse aggregate (gravel or granite) and water. Admixtures are occasionally added.

\subsubsection{Strength of Concrete}

The maximum load or stress a concrete could withstand is referred to as its strength. The potential strength of concrete is determined by the properties and composition of its embedded material. The compressive strength of concrete is commonly used in the construction industry for the purpose of specification and quality control. A primary function of all structures is to carry load or resist applied forces of whatever nature, other functions such as retention of fluids, or exclusion of water or other destructive agents may be involved too in order to maintain sonority of structure without failure or cranking tensile strength of special, importance, although its actual magnitude is relatively low, usually steel, reinforcement is provided to resist tensile forces. The proportion of water to cement determines the strength, the age of the concrete, the quality as well as the mix and shape of the specimen tested. 
A specimen tested for compressive strength will have a higher indicated strength if the specimen is dry before testing whereas flexural strength will be lower in a dry specimen, strength must be carefully planned, designed and controlled.

\subsection{Effects of Salinity on Concrete}

As said earlier, the direct action of soluble salts results in salt attack, while the problems associated with salinity are often regarded to simply as salt damp, it is important to note that there exist many different salts that can be present, each possessing a different deterioration mechanism in terms of concrete. Since the usual test for salinity is the electrical total conductivity test which measures only the total soluble salt, it provides not an indication as to which types are present by knowing the composition of salts present, but precise assessment of the salt attack mechanism and durability requirements of concrete elements can be made and more effective salinity management strategies are implemented.

\section{METHODOLOGY}

\section{Materials Used}

\subsection{Cement}

The Dangote Portland 3X brand of cement from a single batch was used for the entire work and care has been taken that it has to been stored in airtight containers to prevent it from being affected by moisture and humidity.

\subsection{Aggregate}

Aggregate is either fine aggregate or coarse aggregate. Sand is an example of fine aggregate which is naturally occurring granular material composed of finely divided rock and mineral particles. The aggregate which passed through $4.75 \mathrm{~mm}$ is called fine aggregate. The aggregate which is retained above $4.75 \mathrm{~mm}$ sieve is called coarse aggregate.

\subsection{Fresh water}

Ordinary clean portable and fresh water free from suspended particles and chemical substances was used for both mixing and curing of concrete cubes cast with samples for the control experiment. Mixing water for concrete is usually required to be fit for drinking or to be taken from an approved source. This is to ensure that the water is reasonably free from impurities such as suspended solids, organic matter and dissolve salts.

\subsection{Salt water:}

Seawater is water from a sea or ocean. It is known that every kilogram of seawater has approximately 35 grams of dissolved salts (predominantly sodium $(\mathrm{Na}+)$ and chloride $(\mathrm{Cl}-)$ ions). But in this Experiment, some measured quantities of salt was dissolved in water to produced $(5 \mathrm{mg} / \mathrm{l}),(10 \mathrm{mg} / \mathrm{l})$ and $(15 \mathrm{mg} / \mathrm{l})$ of salts water.

\subsection{Bar Sizes}

Bar sizes used in this work were of diameter $8 \mathrm{~mm}$, and $12 \mathrm{~mm}$, and the length of each of these bars was approximately $250 \mathrm{~mm}$.All the bars were the deformed type. The reinforcing steel was purchased with the stipulation that the rebar be as free from corrosion as was possible.

\subsection{Experimental Program}

In this study we cast and cure concrete using fresh water and Salt water. The saline water was prepared by adding salt in different proportions by volume of water I,e (grams/litre) $(5 \mathrm{gm}),(10 \mathrm{gm})$ and $(15 \mathrm{gm})$. A totals of four eight (48) specimens were cast compressive strength test. Also twelve (12) Nos specimens of cylinder size $150 \mathrm{~mm} x$ $300 \mathrm{~mm}$ was cast for tensile test. The prepared specimens were cured for 7 days, 14 days, 21 days and 28 days in Fresh water and Saline water and were tested for compressive strength and split tensile strength. 


\section{RESULTS AND DISCUSSION}

\subsection{Introduction}

In order to achieve the objective of this research program, various laboratory tests were conducted on the concrete, the reinforcement, and the reinforced concrete. Below is a detailed discussions on the results obtained. The analysis is presented in tables 4.1 to 4.8 and Fig. 4.1 to fig. 4.5

\subsection{Test Results}

Table 4.1 Summary of compressive strength development with age for concrete produced with fresh water.

\begin{tabular}{|l|l|l|l|l|}
\hline Days & 7 & 14 & 21 & 28 \\
\hline Compressive strength $\left(\mathrm{N} / \mathrm{mm}^{2}\right)$ & 18.4 & 23.8 & 26.1 & 28.7 \\
\hline
\end{tabular}

Table 4.2 Summary of compressive strength development with age for concrete produced with $5 \mathrm{gm} / \mathrm{l}$ of salt water.

\begin{tabular}{|l|l|l|l|l|}
\hline Days & 7 & 14 & 21 & 28 \\
\hline Compressive strength $\left(\mathrm{N} / \mathrm{mm}^{2}\right)$ & 18.8 & 21.4 & 23.9 & 26.3 \\
\hline
\end{tabular}

Table 4.3 Summary of compressive strength development with age for concrete produced with $10 \mathrm{gm} / \mathrm{l}$ of salt water.

\begin{tabular}{|l|l|l|l|l|}
\hline Days & 7 & 14 & 21 & 28 \\
\hline Compressive strength $\left(\mathrm{N} / \mathrm{mm}^{2}\right)$ & 19.1 & 20.5 & 22.1 & 24.2 \\
\hline
\end{tabular}

Table 4.4 Summary of compressive strength development with age for concrete produced with $20 \mathrm{gm} / \mathrm{l}$ of salt water.

\begin{tabular}{|l|l|l|l|l|}
\hline Days & 7 & 14 & 21 & 28 \\
\hline Compressive strength $\left(\mathrm{N} / \mathrm{mm}^{2}\right)$ & 17.3 & 19.0 & 21.1 & 22.5 \\
\hline
\end{tabular}

Table 4.5 Split tensile Strength Of reinforced Concrete produced with fresh water

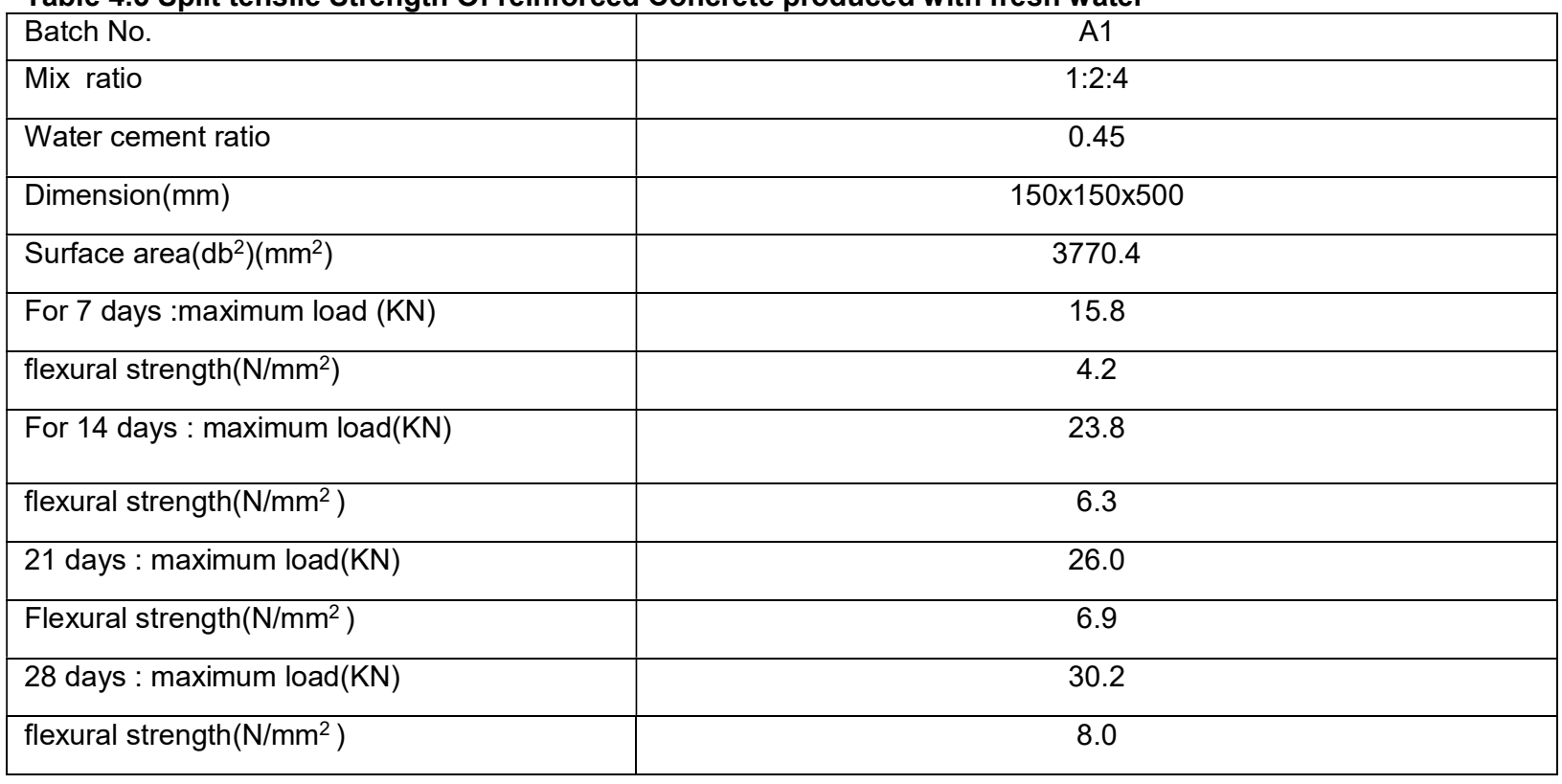


Advances In Multidisciplinary

Aes \& Scientifie Research

Vol. 4 No. 4, December, 2018

Table 4.6 Split tensile Strength Of reinforced Concrete produced with $5 \mathrm{gm} / \mathrm{l}$ salt water

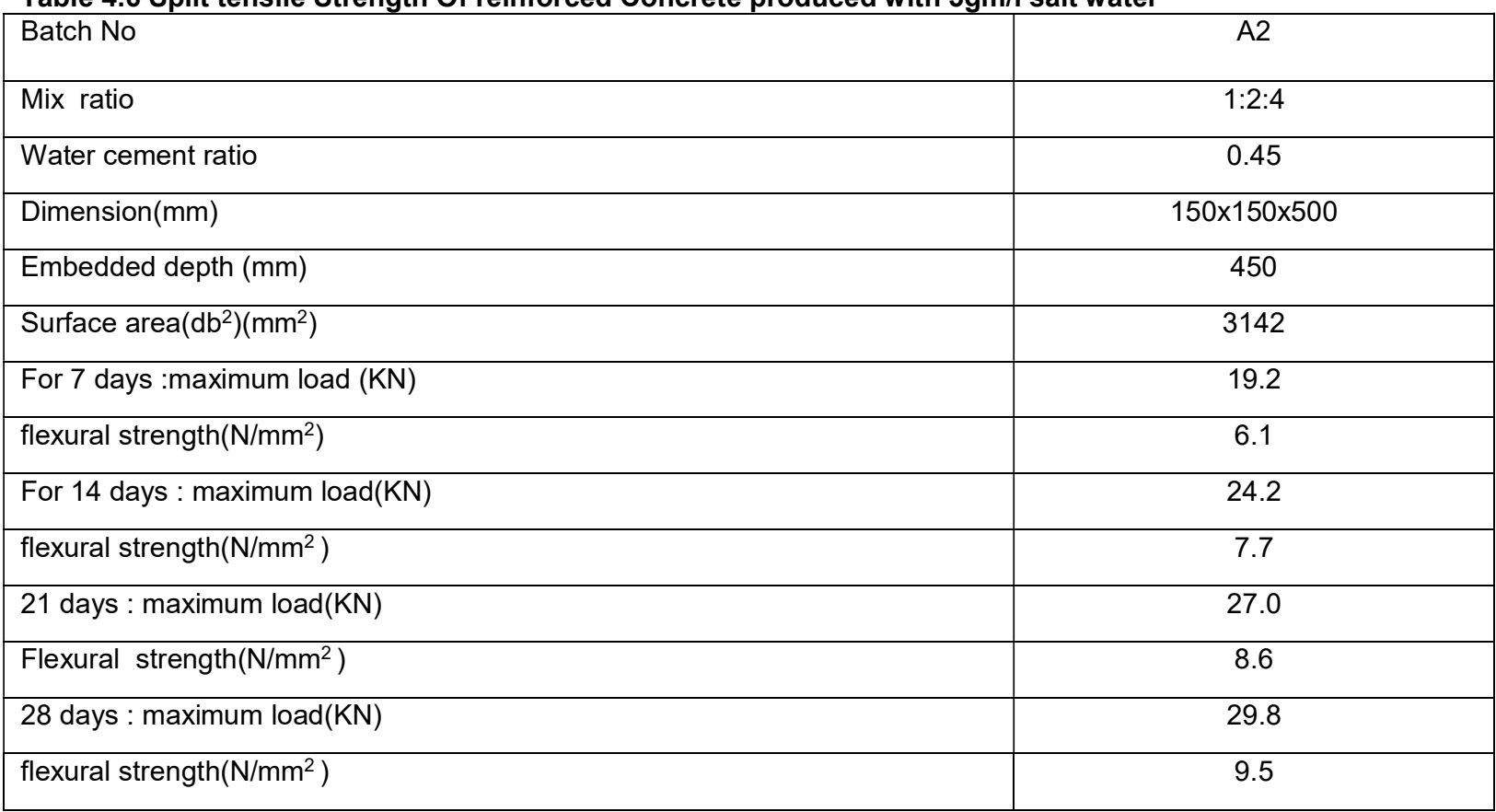

Table 4.7 Split tensile Strength Of reinforced Concrete produced with $10 \mathrm{gm} / \mathrm{l}$ salt water

\begin{tabular}{|c|c|}
\hline Batch No. & A3 \\
\hline Mix ratio & $1: 2: 4$ \\
\hline Water cement ratio & 0.45 \\
\hline $\operatorname{Dimension}(\mathrm{mm})$ & $150 \times 150 \times 500$ \\
\hline Surface area $\left(\mathrm{db}^{2}\right)\left(\mathrm{mm}^{2}\right)$ & 3770.4 \\
\hline For 7 days :maximum load (KN) & 18.5 \\
\hline flexural strength $\left(\mathrm{N} / \mathrm{mm}^{2}\right)$ & 4.9 \\
\hline For 14 days : maximum load(KN) & 25.6 \\
\hline flexural strength $\left(\mathrm{N} / \mathrm{mm}^{2}\right)$ & 6.8 \\
\hline 21 days : maximum load(KN) & 29.0 \\
\hline Flexural strength(N/mm²) & 7.7 \\
\hline 28 days : maximum load $(\mathrm{KN})$ & 36.2 \\
\hline flexural strength $\left(\mathrm{N} / \mathrm{mm}^{2}\right)$ & 9.6 \\
\hline
\end{tabular}


Advances In Multidisciplinary

Aess \& Scientifie Research

Vol. 4 No. 4, December, 2018

Table 4.8 Split tensile Strength Of reinforced Concrete produced with $20 \mathrm{gm} / \mathrm{l}$ salt water

\begin{tabular}{|c|c|}
\hline Batch No & A4 \\
\hline Mix ratio & $1: 2: 4$ \\
\hline Water cement ratio & 0.45 \\
\hline Dimension $(\mathrm{mm})$ & $150 \times 150 \times 500$ \\
\hline Embedded depth (mm) & 450 \\
\hline Surface area $\left(\mathrm{db}^{2}\right)\left(\mathrm{mm}^{2}\right)$ & 3142 \\
\hline For 7 days :maximum load (KN) & 28 \\
\hline flexural strength $\left(\mathrm{N} / \mathrm{mm}^{2}\right)$ & 7.0 \\
\hline For 14 days : maximum load(KN) & 28 \\
\hline flexural streng:4th(N/mm² $)$ & 8.9 \\
\hline 21 days : maximum load(KN) & 31.4 \\
\hline Flexural strength(N/mm²) & 10.0 \\
\hline 28 days : maximum load(KN) & 41.2 \\
\hline flexural strength $\left(\mathrm{N} / \mathrm{mm}^{2}\right)$ & 13.1 \\
\hline
\end{tabular}

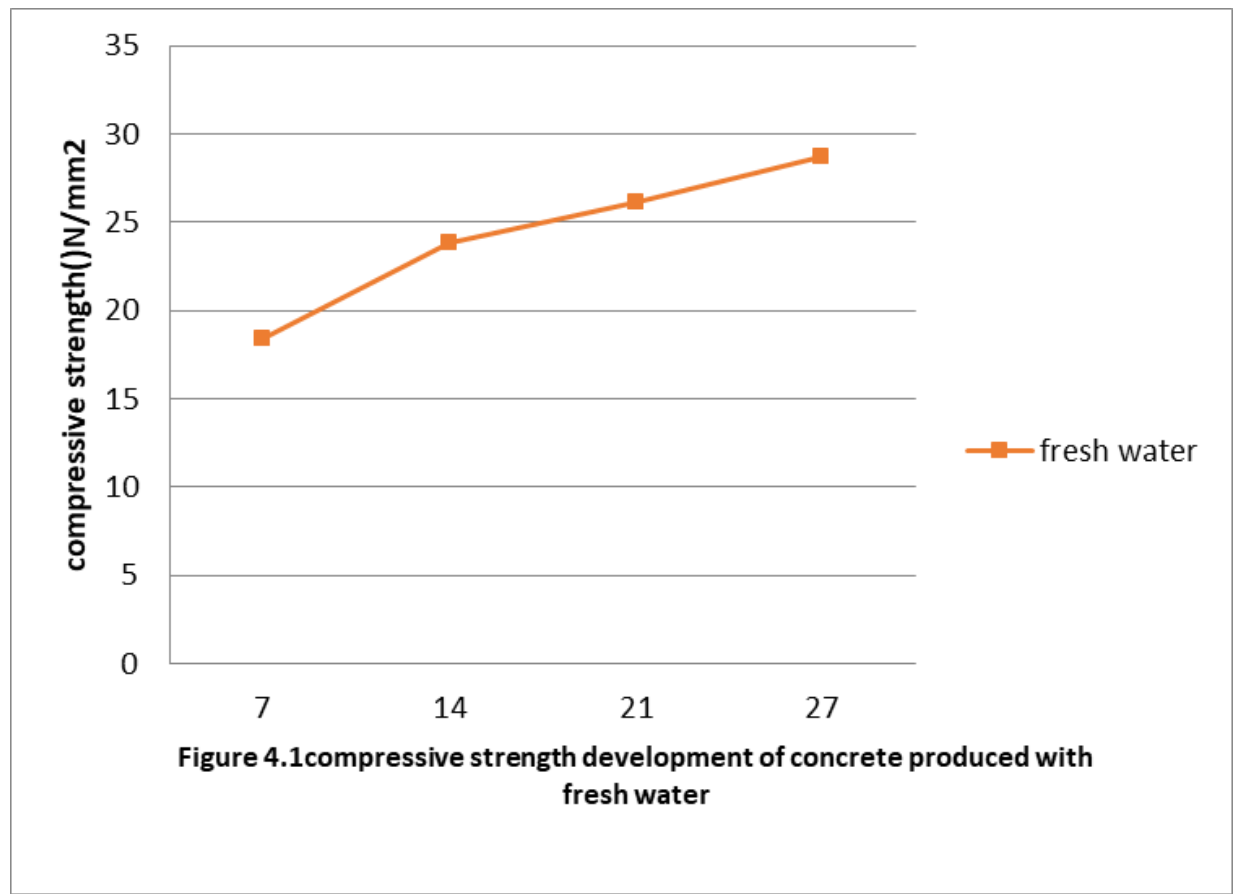


Advances In Multidisciplinary

Res \& Scientifie Research

Vol. 4 No. 4, December, 2018

A Multidisciplinary \& Interdisciplinary Journal
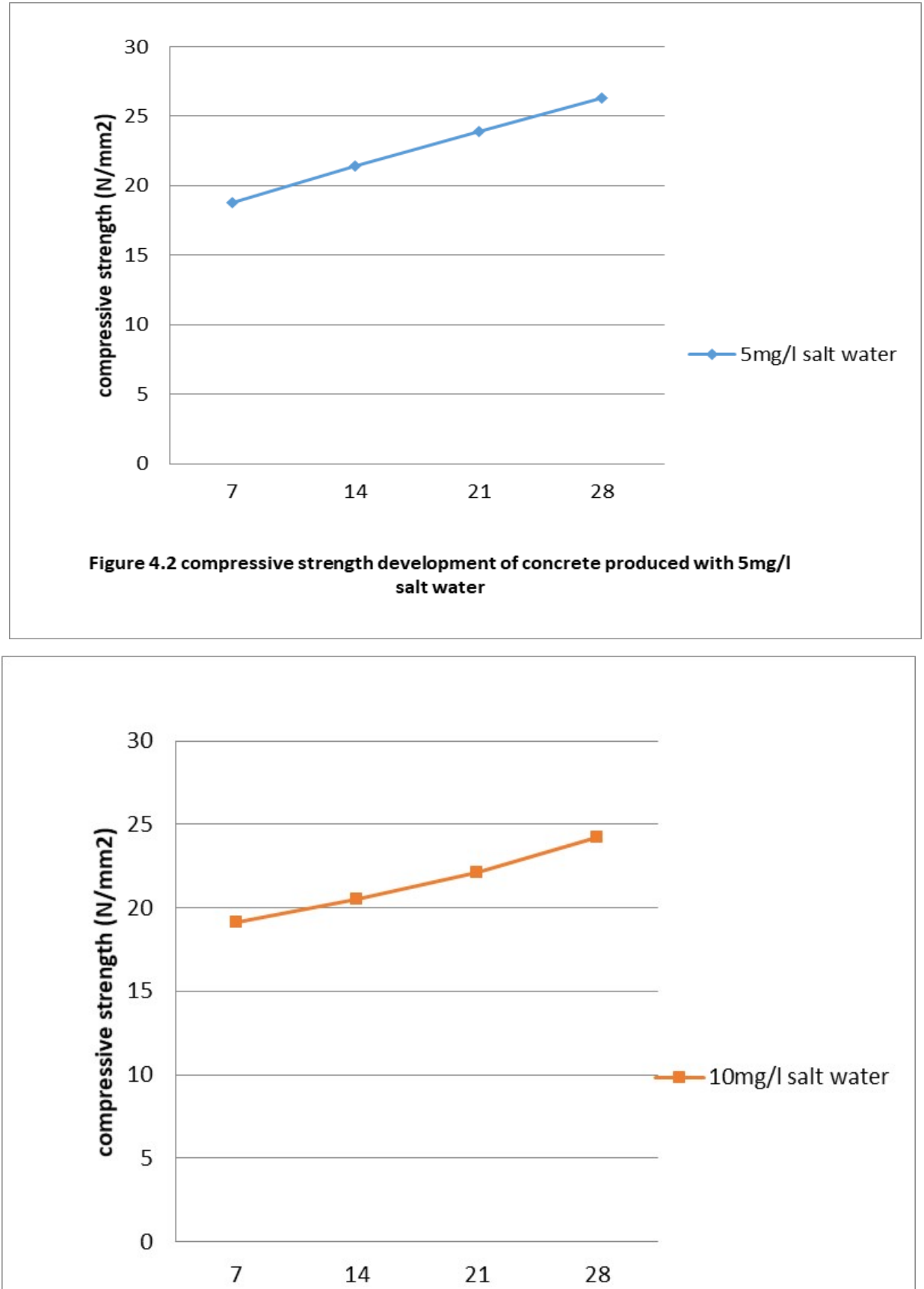

Figure 4.3 compressive strength development of concrete produced with $10 \mathrm{mg} / \mathrm{I}$ salt water 
Advances In Multidisciplinary

A. Pis \& Scientifie Research

Vol. 4 No. 4, December, 2018

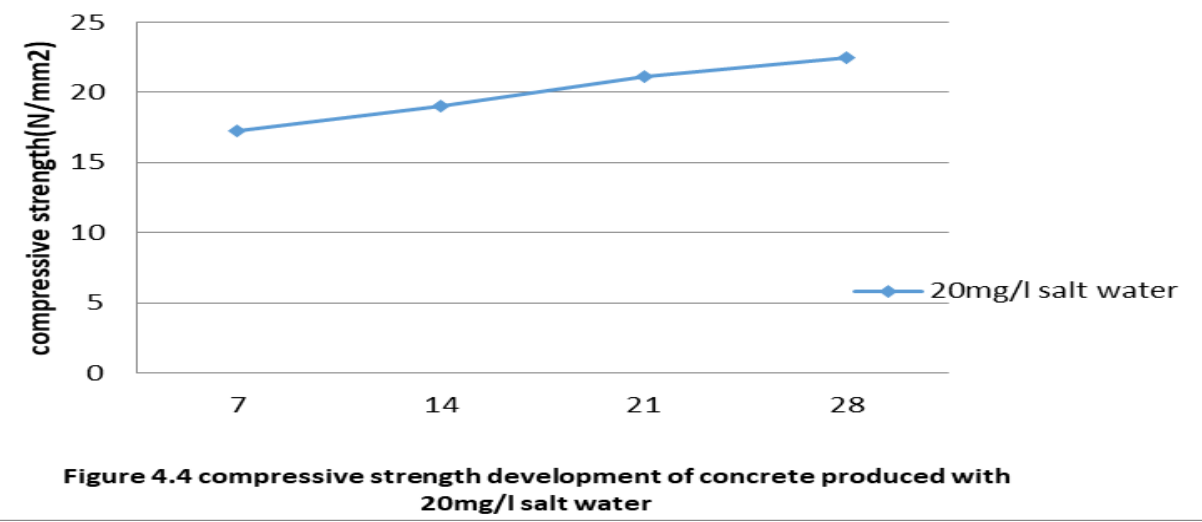

$20 \mathrm{mg} / \mathrm{I}$ salt water

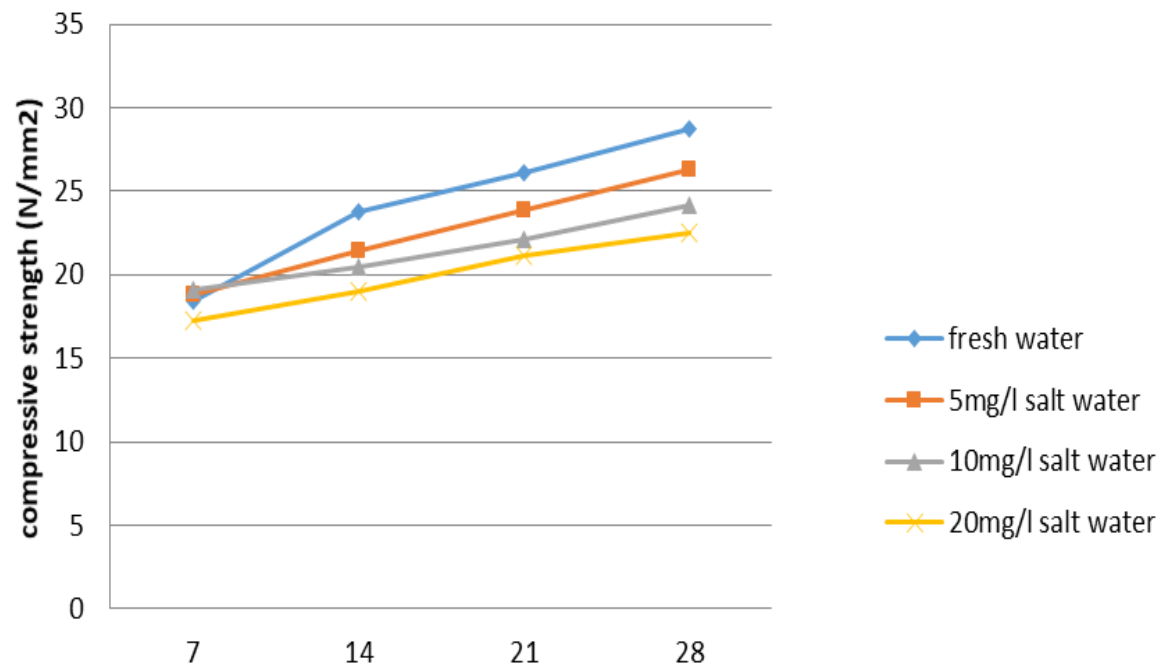

Figure 4.5 rate of compressive strength development of concrete produced with both fresh and salt water 


\subsection{Discussion of Results}

Mix proportion of 1:1.5:3 with water cement ratio of 0.40 . was adopted.Table 4.1 to 4.4 showed the rate of compressive strength development with age, table 4.5 to 4.8 showed the result of split strength test .The relationship between the compressive strength and age of concrete using the mix ratio are as shown in Fig. 4.1 - 4.5, it was deduce there were no reduction in the strength if we use salt water casting and curing the concrete. There is some increase in the strength if salt water as used for casting and curing. This concrete can be used for mass concreting without any decrease in strength properties.

\section{CONCLUSIONS AND RECOMMENDATION}

\subsection{Conclusions}

i. There is marginal increase in the strength of cubes and cylinder cast and cured in salt water as compared to those of cast and cured in fresh water at all ages of curing.

ii. From the above finding we can conclude that there is no reduction in the strength if we use salt water casting and curing the concrete. There is some increase in the strength if salt water is used for casting and curing

iii. It therefore infers that reinforced concrete structures on saline environment are safe with adequate concrete cover.

\subsection{Recommendations}

The following recommendations were drawn:

(i) It is recommended for subsequent investigation to do more testing to verify and make some enhancement for a better performance with all types of concrete (high strength type), and with different concrete mix

(ii) It is recommended that more work be done in this project, by way of trying to achieve high strength concrete using of additive.

(iii) Also variable concrete dimensions should be used in subsequent research.

\section{REFERENCES}

1. Akinkurolere, O. O., Jiang, C and Shobola O. M. (2007) "The Influence of Salt Water on the Compressive Strength of Concrete", Journal of Engineering and Applied Sciences, Vol. 2 No. 2, pp. 412 - 415.

2. Esfahani, M. R., and Rangan, B. V. (2000). "Local Bond Strength of Reinforcing Bars in Normal Strength and High-Strength Concrete." ACI Structural Journal, 95(2), 96-106.

3. Gopa, F. H.,(2010) Water repellent treatment as applied to protect reinforced concrete structures, Concrete (China) 24 (6), 14-16.

4. Medeiros, M. and Helene, P. (2008) Efficacy of surface hydrophobic agents in reducing water and chloride ion penetration in concrete, Mat. And Struct. 41, 59-71.

5. Mehta, P. K. (1980). "Mineral admixtures for concrete - An overview of Recent Developments Advances in Cement and Concrete" Proc of Eng Foundation Conference, (Ed.) MW Gutzeck, SL Sarkar, pp: 243-256.

6. Mokhar, S. J. and Swamy F. H., (2008) Water repellent treatment of concrete surfaces - Recommendations for design and application, (German and French) Swiss Federal Roads Authority, Swiss Association of Road and Transportation Experts (VSS), Report No.

7. Osei, D.C. (2000) "Long Term Performance of Plain and Reinforced Concrete in Seawater Environments", Portland cements Association, RD 119, and Retrieved December 01,2010.

8. Oyenuga, V. O. (2004). Design and Construction of Foundations1st Edition by Asros Ltd. Lagos Nigeria.

9. Parrott, L., J.(2006) Some effects of cement and curing upon carbonation and reinforcement corrosion in concrete Materials and Structures, Volume 29, Issue 3, pp 164-173.

10. Prascal, T. Zhao, G. Zhu, F. H. Wittmann, and W. Li,(2006) On surface impregnation of chloride contaminated cement based materials, another contribution to this volume, pp. 311-324.

11. Schweitzer,A. M., (2010) Drying Shrinkage and Crack Formation, Building Materials Reports No. 5, Aedificatio Publishers Freiburg.

12. Stark, C. L.,(2001) The mechanisms of moisture flow through porous materials, in Werkstoffwissenschaften und Bausanierung, Proc. 2. Int. Colloquium, Technische Akademie Esslingen (TAE), F. H. Wittmann, editor, pp. 599-605.

13. Tibbetts, D. C. (1968) "Performance of Concrete in Seawater", Canadian Blding Series, No.2, pp. 159 - 180.

14. Villmann, B. (2007) Determination of the diffusion coefficient by inverse analysis of drying experiments, 5th Int. Essen Workshop on Transport in Concrete: Nano- to Macro-structure M. Setzer editor, Aedificatio Publishers, pp. 127-136

15. Wittmann, F. H. (1982) Creep and shrinkage mechanisms, in Creep and Shrinkage in Concrete Structures, Z. P. Bazant and F. H. Wittmann, editors, John Wiley \& Sons, pp. 129- 161 